\title{
ROLE OF ESMOLOL AND SODIUM NITROPRUSSIDE AS HYPOTENSIVE AGENTS IN FUNCTIONAL ENDOSCOPIC SINUS SURGERIES
}

\author{
Fayaz Ahmad Munshi', Farhana Bashir², Saba Ahad³, Mushtaq Ahmad Rather ${ }^{4}$ \\ ${ }^{1}$ Associate Professor, Department of Anesthesiology and Critical Care, GMC, Srinagar. \\ ${ }^{2}$ Senior Resident, Department of Anesthesiology and Critical Care, GMC, Srinagar. \\ ${ }^{3}$ Senior Resident, Department of Anesthesiology and Critical Care, GMC, Srinagar. \\ ${ }^{4}$ Senior Resident, Department of Anesthesiology and Critical Care, GMC, Srinagar.
}

\section{ABSTRACT}

\section{BACKGROUND}

Present study was conducted to evaluate the efficacy of esmolol and sodium nitroprusside as hypotensive agents in functional endoscopic surgeries.

\section{METHODS}

Forty patients of age group 18-60 years and ASA I and II physical status scheduled for Functional Endoscopic Surgeries (FESS) were randomly assigned into two groups of twenty patients each. Patients in group A received Sodium Nitroprusside (SNP) 0.5$10 \mu \mathrm{g} / \mathrm{kgwt} / \mathrm{min}$. infusion after induction of anaesthesia and patients in group B received loading dose of Esmolol (ESM) $1 \mathrm{mg} / \mathrm{kgwt}$ infused over 1 minute followed by maintenance rate of $0.4-0.8 \mu \mathrm{g} / \mathrm{kgwt} / \mathrm{hr}$.

\section{RESULTS}

In both the groups, the desired MAP was achieved but the bleeding was more in SNP group than ESM groups and the intraoperative heart rate remained on lesser side in ESM group.

\section{CONCLUSION}

It was observed that esmolol infusion resulted in lesser bleeding and better surgical fields during surgery as compared to sodium nitroprusside infusion. Also esmolol resulted in better hemodynamics intraoperatively as compared to SNP.

\section{KEYWORDS}

Controlled Hypotension, Functional Endoscopic Surgery, Esmolol, Sodium Nitroprusside.

HOW TO CITE THIS ARTICLE: Fayaz Ahmad Munshi, Farhana Bashir, Saba Ahad, Mushtaq Ahmad Rather. "Role of Esmolol and Sodium Nitroprusside as Hypotensive Agents in Functional Endoscopic Sinus Surgeries." Journal of Evolution of Medical and Dental Sciences 2015; Vol. 4, Issue 96, November 30; Page: 16171-16174, DOI: 10.14260/jemds/2015/2374

\section{INTRODUCTION}

Deliberate hypotension is a common technique to decrease bleeding and improve surgical field visualisation during surgeries like FESS.[1] FESS is performed in patients who suffer from diseases like chronic sinusitis, antrochoanal polyposis, nasal mucoceles etc. in whom medical treatment has failed.[2] Till now several drugs have been used for inducing controlled hypotension during surgeries like infusion of nitroglycerine, Sodium Nitroprusside (SNP), esmolol, labetalol etc. We conducted this study in order to compare the efficacy of esmolol with sodium nitroprusside infusion for inducing controlled hypotension in FESS.

\section{MATERIAL AND METHOD}

This double blind randomized study was conducted in the Department of Anaesthesiology and critical care GMC Srinagar. Forty patients of ASA I and II physical status in the age group of 18-60 years scheduled for FESS were randomly assigned into two groups of 20 patients each. Patients excluded from our study were following:

Financial or Other, Competing Interest: None.

Submission 08-11-2015, Peer Review 09-11-2015,

Acceptance 20-11-2015, Published 28-11-2015.

Corresponding Author:

Mushtaq Ahmad Rather,

Senior Resident,

Department of Anesthesiology and Critical Care,

GMC,

Srinagar-190006

E-mail: mushtaqahmad767@gmail.com

DOI:10.14260/jemds/2015/2374
- Patients preferring local anaesthesia,

- Patients taking cardiovascularly active drugs, and

- Patients on drugs influencing blood coagulation.

After getting written informed consent from the patients, premedication in the form of inj. pantoprazole and inj. midazolam $0.5-1 \mathrm{mg}$ IV was given. Anaesthesia technique in all patients was standardised, which included inj. fentanyl $0.5-2 \mu \mathrm{g} / \mathrm{kgwt}$ IV 2-3 minutes before induction of anaesthesia with inj. propofol $2 \mathrm{mg} / \mathrm{kgwt}$ plus inj. rocuronium 0.6 $1.2 \mathrm{mg} / \mathrm{kgwt} ; 50 \%$ nitrous oxide with oxygen and $1 \%$ isoflurane were used for maintenance of anaesthesia. Group $\mathrm{A}(\mathrm{SNP})$ received inj. SNP $0.5-10 \mu \mathrm{g} / \mathrm{kg} / \mathrm{min}$. titrated to desired MAP $(60-70 \mathrm{mmHg})$. Patients in group B(ESM) patients received inj. esmolol $1 \mathrm{mg} / \mathrm{kgwt}$ over one minute after induction of anaesthesia and then maintenance dose of 0.4 $0.8 \mu \mathrm{g} / \mathrm{kg} / \mathrm{hr}$. titrated till target MAP achieved $(60-70 \mathrm{mmHg})$.

Monitoring of the patients was done by using electrocardiogram, pulse oximetery, capnography and invasive blood pressure measurement (Using 20 gauge cannula for arterial cannulation).

Assessment of blood loss was done by the operating surgeon with 6 point category scale: 0 -no bleeding; 1 -slight bleeding, no suctioning of blood required; 3-slight bleeding, frequent suctioning required, bleeding threatens surgical field a few seconds after suction is removed; 4-moderate bleeding, frequent suctioning required, bleeding threatens surgical field directly after suction is removed; 5-severe bleeding, constant suctioning required, bleeding appears faster than can be removed by suctioning, surgical field severely threatened and surgery not possible. 
Anaesthetist as well the surgeon remained blinded to the type of drug used for controlled hypotension during FESS. Before a few minutes of completion of surgery, infusion was stopped and patients were reversed, extubated and shifted to recovery for observation.

\section{RESULTS}

Forty patients were enrolled in this study undergoing FESS (20 each ESM and SNP group). All patients were able to complete the entire study and their data were included in the final analysis. The demographic data, duration of surgery, intraoperative blood loss, and duration of anesthesia were compared between the two groups. All the groups were comparable in terms of age, sex, weight, duration of surgery, and duration of anesthesia (Table 1).

\begin{tabular}{|c|c|c|c|}
\hline Parameter & Group A(SNP) & Group B(ESM) & P-Value \\
\hline Age(yrs) & $42.12 \pm 10.07$ & $39.12 \pm 12.77$ & 0.190 \\
\hline Male : Female & $8: 7$ & $7: 8$ & 0.980 \\
\hline Weight(kg) & $63.12 \pm 8.92$ & $60 \pm 8.95$ & 0.582 \\
\hline ASA I: ASA II & $9: 6$ & $7: 8$ & 0.791 \\
\hline $\begin{array}{c}\text { Duration of } \\
\text { Anaesthesia } \\
\text { (min) }\end{array}$ & $94.08 \pm 9.55$ & $93.03 \pm 8.65$ & 0.910 \\
\hline $\begin{array}{c}\text { Duration of } \\
\text { Surgery(min) }\end{array}$ & $83.08 \pm 9.45$ & $81.03 \pm 10.45$ & 0.139 \\
\hline \multicolumn{4}{|c|}{ Table.1: Demographic Profile of Patients } \\
\hline
\end{tabular}

statistically insignificant throughout the procedure time. (Table 2 and Fig. 1).

\begin{tabular}{|c|c|c|c|}
\hline \multirow[t]{2}{*}{ Preoperative } & $\begin{array}{c}\text { Group A } \\
\text { (SNP) }\end{array}$ & $\begin{array}{c}\text { Group B } \\
\text { (ESM) }\end{array}$ & $\begin{array}{c}\text { P- } \\
\text { Value }\end{array}$ \\
\hline & $92.8 \pm 9.5$ & $90.7 \pm 9.2$ & 0.10 \\
\hline Post induction & $82.1 \pm 6.5$ & $79.9 \pm 6.7$ & 0.22 \\
\hline 15 min intraoperative & $67.8 \pm 5.9$ & $63.7 \pm 6.2$ & 0.91 \\
\hline 30 min intraoperative & $63.7 \pm 6.0$ & $62.1 \pm 5.7$ & 0.72 \\
\hline 45 min intraoperative & $62.8 \pm 5.5$ & $62.9 \pm 6.5$ & 0.87 \\
\hline 60 min intraoperative & $64.4 \pm 4.5$ & $63.7 \pm 5.3$ & 0.76 \\
\hline $\begin{array}{c}5 \text { min after stopping } \\
\text { hypotensive agent }\end{array}$ & $80.7 \pm 5.3$ & $79.5 \pm 6.5$ & 0.04 \\
\hline $\begin{array}{c}10 \text { min after stopping } \\
\text { hypotensive agent }\end{array}$ & $87.9 \pm 8.9$ & $86.3 \pm 9.0$ & 0.13 \\
\hline After recovery & $93.4 \pm 7.9$ & $92.5 \pm 8.3$ & 0.61 \\
\hline \multicolumn{4}{|c|}{$\begin{array}{c}\text { Table 2: Mean Arterial Pressure Values (mmHg) in the } \\
\text { Sodium Nitroprusside (SNP) and Esmolol (ESM) Groups at } \\
\text { Different Times }\end{array}$} \\
\hline
\end{tabular}

Significant value: $\mathrm{p}$ value $<0.05$

Blood loss was significantly less in the ESM group than in the SNP. The changes in MAP between the two groups were

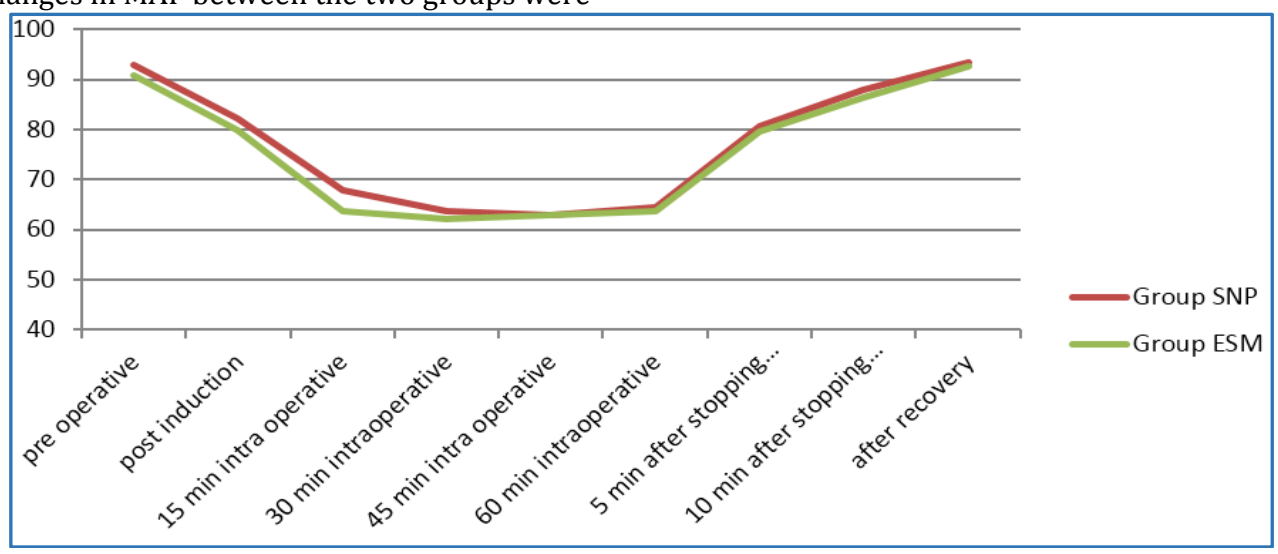

Fig. 1: Showing Mean Arterial Pressure (MAP) in mmHg at Different Times

The changes in HR between the two groups were statistically insignificant at preoperative and after recovery, but were significantly lower in the ESM group than the SNP group at post induction, $15 \mathrm{~min}$. intraoperative, $30 \mathrm{~min}$. intraoperative, $45 \mathrm{~min}$. intraoperative, 60 min. intraoperative. (Table 3 and Fig. 2).

There were no episodes of severe hypotension (MAP of $60 \mathrm{mmHg}$ ) or severe bradycardia (HR of 50 beats/min.) during infusion of the hypotensive agents in both groups.

\begin{tabular}{|c|c|c|c|}
\hline \multirow[t]{2}{*}{ Preoperative } & $\begin{array}{c}\text { Group A } \\
\text { (SNP) }\end{array}$ & $\begin{array}{c}\text { Group B } \\
\text { (ESM) }\end{array}$ & P-Value \\
\hline & $83.4 \pm 8.6$ & $81.6 \pm 8.9$ & 0.67 \\
\hline Post induction & $70.2 \pm 7.9$ & $66.6 \pm 8.0$ & 0.03 \\
\hline 15 min intraoperative & $89.4 \pm 5.9$ & $62.2 \pm 6.0$ & 0.01 \\
\hline 30 min intraoperative & $88.1 \pm 5.9$ & $60.0 \pm 6.0$ & 0.03 \\
\hline 45 min intraoperative & $90.5 \pm 4.7$ & $63.2 \pm 5.0$ & 0.01 \\
\hline 60 min intraoperative & $92.9 \pm 4.5$ & $64.7 \pm 5.5$ & 0.01 \\
\hline 5 min after stopping hypotensive agent & $79.6 \pm 5.7$ & $76.3 \pm 6.8$ & 0.78 \\
\hline 10 min after stopping hypotensive agent & $78.2 \pm 8.1$ & $80.8 \pm 8.9$ & 0.59 \\
\hline After recovery & $80.9 \pm 9.0$ & $83.6 \pm 7.9$ & 0.78 \\
\hline
\end{tabular}


Significant value: $\mathrm{p}$ value $<0.05$

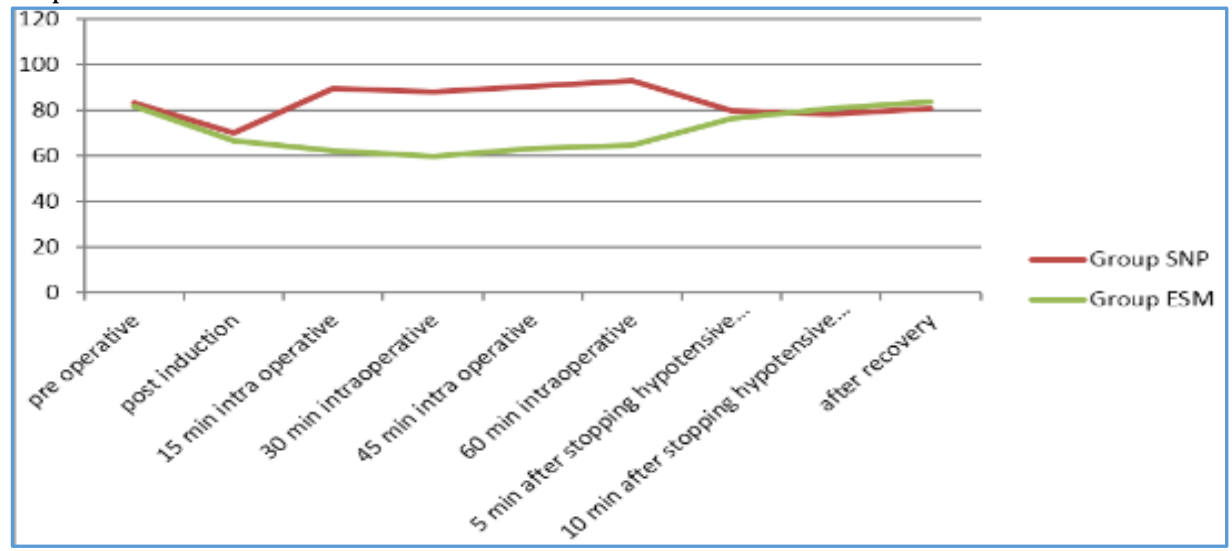

Fig. 2: Showing Mean Heart Rates (BPM) at Different Times

The operative field conditions were significantly better in the ESM group than the SNP and ESM at 15, 30, 45 and 60 min. after beginning of the surgery. (Fig. 3).

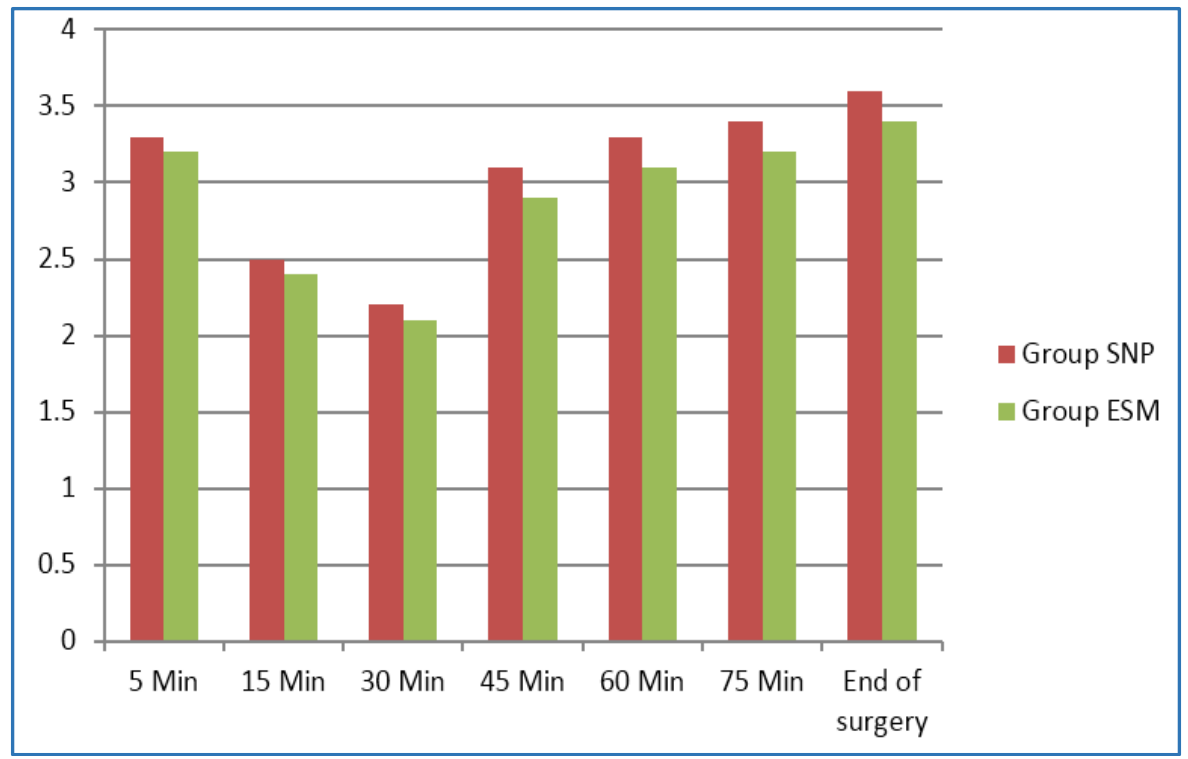

Fig. 3: Quality of Operative Field Evaluated using the Quality Scale of Fromm and Boezaart

\section{DISCUSSION}

Due to the promising clinical results, FESS is becoming a widely performed surgery to restore the natural mucociliary clearance mechanism, drainage and aeration of sinuses. ${ }^{[3,4,5]}$ Good surgical visibility and minimal bleeding results in better surgical outcome in FESS. Controlled hypotension is one such technique that helps reduce bleeding in surgical field. In controlled hypotension, the aim is to reduce MAP $60 \mathrm{mmHg}$ recoverably and intentionally and maintaining it at this level throughout the procedure.[6]

In our study we used two hypotensive agents, esmolol and SNP. We compared their efficacy in terms of reduction of bleeding and subsequently improvement in the surgical field. It was observed that there was lesser bleeding and better surgical field visualisation in group B(ESM group) as compared to group A(SNP group). Also SNP resulted in tachycardia intraoperatively as compared to esmolol.

The reason for our observation is that SNP causes vascular smooth muscle relaxation and vasodilatation, which causes reflex tachycardia and increased cardiac output and blood flow in the mucous membranes and hence increased bleeding. While as esmolol being $\beta 1$ adrenoceptor antagonist. [7] causes vasoconstriction of mucous membrane arterioles added by unopposed $\mu$ adrenergic action and hence reduced bleeding. It also results in decreased heart rate due to its $\beta 1$ antagonist action on heart. Therefore esmolol, besides resulting in reduced surgical bleeding also results in better hemodynamics intraoperatively.

Our results are in accordance with Chan et al.[8] who observed a $20 \%$ reduction in MAP and reduced bleeding with esmolol infusion. Fromme et al.[9] also observed that there was not much improvement in surgical field visualisation in orthognathic surgeries after giving SNP infusion.

Boezaart et al.[10] observed that esmolol resulted in better surgical field conditions than SNP. Hersey et al.[11] noted that blood loss was more severe in SNP group in patients undergoing spinal surgery for idiopathic scoliosis as compared to patients receiving nicardipine for controlled hypotension.

\section{CONCLUSION}

It can be concluded from our study that esmolol infusion results in reduced bleeding, better surgical visualisation and intraoperative hemodynamics as compared to SNP infusion during FESS. 


\section{REFERENCES}

1. Tobias JD. Controlled hypotension in children: A critical review of available agents. Paediatr Drugs 2002;4:439453.

2. Ankit Patel, MD; Chief Editor: Arlen D Meyers, MD, MBA; Functional endoscopic sinus surgery overview Updated December 14, 2014.

3. Messerklinger W. Endoscopy of the Nose. BaltimoreMunich 1978: Urban and Schwarzenberg 1978:1-54.

4. Stammberger H. Endoscopic endonasal surgeryconcepts in treatment of recurring rhinosinusitis. Otolaryngol Head Neck Surg 1986;94:143-56.

5. Stammberger H. Functional Endoscopic Sinus Surgery. Philadelphia: BC Decker 1991;321-33.

6. ElGohary MM, Arafa AS. Dexmedetomidine as a hypotensive agent: efficacy and hemodynamic response during spinal surgery for idiopathic scoliossis in adolescents. Egypt J Anesth 2010;26:305-311.
7. Blowey DL. Antihypertensive agents: Mechanisms of action, safety profiles, and current uses in children. Curr Ther Res Clin Exp 2001;62:298-313.

8. Chan W, Smith DE, Ware WH. Effects of hypotensive anesthesia in anterior maxillary osteotomy. Oral Surg 1980;38:504-8.

9. Fromme GA, MacKenzie RA, Gould AB, Lurid BA, Offord KP. Controlled hypotension for orthognathic surgery. Anesth Analg 1986;65:683-6.

10. Boezaart AP, Van Der Merwe J, Coetzee A. Comparison of sodium nitroprusside- and esmolol-induced controlled hypotension for functional endoscopic sinus surgery. Can J Anaesth 1995;42:373-376.

11. Hersey SL, O’Dell NE, Lowe S, Rasmussen G, Tobias JD, Deshpande JK, et al. Nicardipine versus nitroprusside for controlled hypotension during spinal surgery in adolescents. Anesth Analg 1997;84:1239-1244. 